\title{
КЛИНИЧЕСКИЙ СЛУЧАЙ ПМСР: РАК МОЛОЧНОЙ ЖЕЛЕЗЫ И МЕЛАНОМА КОЖИ
}

\section{PMSR CLINICAL CASE: BREAST CANCER AND SKIN MELANOMA}

\author{
A. Magomedova \\ A. Parsadanyan \\ L. Evloeva \\ A. Stepanyan
}

Summary. Working in the field of oncology, one often encounters difficult clinical situations when a patient simultaneously has to fight two or more deadly, malignant nosologies.

The main reason for the detection of new independent tumors of other localities (PMZO) is the improvement of early diagnosis and the development of new methods of treatment of malignant tumors, which leads to an increase in the survival rate of patients, thereby increasing the likelihood of Primary-multiple malignant tumors (PMMT) [3, 4, 5]. Purpose of the study. Clinical observation of a patient with breast cancer and skin melanoma.

Conclusions. Timely diagnosis, correct diagnosis, and correct treatment leads to long-term remission of cancer and an improvement in the quality of life.

Let's consider one of such clinical cases in the practice of an oncologist.

Keywords: multiple primary synchronous cancer, skin melanoma, breast cancer, a patient, council.

\author{
Магомедова Алена Азетовна \\ Аспирант, Сургутский государственный \\ университет \\ alenushka577@mail.ru \\ Парсаданян Арарат Микичевич \\ Д.м.н, профессор, Сургутский государственный \\ университет \\ Евлоева Лидия Азраиловна \\ Аспирант, Сургутский государственный \\ университет \\ Степанян Арус Араратовна \\ Врач онколог-маммолог, Сургутская ОКБ
}

Аннотация. Работая в сфере онкологии, часто сталкиваешься со сложными клиническими ситуациями, когда пациенту одновременно приходится вести борьбу с двумя и более смертельными, злокачественными нозологиями. Главной причиной выявления новых независимых опухолей других локализаций (ПМЗО) является совершенствование ранней диагностики и разработка новых методов лечения злокачественных опухолей, что приводит к увеличению выживаемости больных, тем самым увеличивая вероятность возникновения ПМЗ2. [3, 4, 5]. Цель исследования. Клиническое наблюдение пациентки с раком молочной железы и меланомой кожи.

Выводы. Своевременная диагностика, верно поставленный диагноз, а также правильное лечение приводит к длительной ремиссии онкологического заболевания и улучшению качества жизни.

Рассмотрим один из таких клинических случаев в практике врача-онколога.

Ключевые слова: первично-множественный синхронный рак, меланома кожи, рак молочной железы, пациент, консилиум.

чин чаще встречаются функционально-зависимые опухоли, к примеру, новообразования верхних и нижних дыхательных путей, а у женщин - гормонально-зависимые раки молочной железы, яичников, толстой кишки [2]. В зависимости от интервала между временем обнаружения опухолей, ПМЗО подразделяются на метахронные (интервал более 6 месяцев) и синхронные (интервал составляет до 6 месяцев) новообразования.

Главной причиной выявления новых независимых опухолей других локализаций (ПМЗО) является совершенствование ранней диагностики и разработка новых методов лечения злокачественных опухолей, что приводит к увеличению выживаемости больных, тем самым увеличивая вероятность возникновения ПМЗО $[3,4,5]$. В 1889 году сначала немецкий хирург T. Billroth [6] пред- 
ложил критерии ПМЗО, затем в 1913 году Goetze [7] видоизменил эти признаки, имеющие определенное значение в клинической практике и в накоплении материала для последующих обобщений в литературе. Им были сформулированы следующие принципы: - макро- и микроскопическая картина опухоли должна быть типичной для органа, в котором она развивалась; - исключение метастазов одной опухоли по отношению к другой; диагноз каждой опухоли может быть подтвержден строением метастазов каждой из них. Как дополнение к этим признакам некоторые исследователи считали исключение опухолей с тенденцией к мультицентрическому росту. Благодаря когортным эпидемиологическим исследованиям установлено, что повышенный риск развития вторых злокачественных опухолей, в большинстве случаев, зависит от пола, локализации первичной опухоли и времени наблюдения за онкологическим больным. По-разному определяется роль последовательных генетических и внешнесредовых факторов в возникновении и развитии ПМЗО. Прогресс в понимании причин, механизмов развития ПМЗО, их диагностики и лечения способствует эволюции взглядов на проблему как синхронной, так и метахронной полинеоплазии [2].

\section{Цель исслемования}

Клиническое наблюдение пациентки с раком молочной железы и меланомой кожи.

Клинический случай (все диагностические манипуляции и виды лечения проведены после взятия информированного добровольного согласия со стороны пациента)

Пациентка Х. в возрасте 62 лет, обратилась к онкологу клинико-диагностической поликлиники Сургутской ОКБ после прохождения скринингового обследования молочных желез с результатами маммографии.

Из анамнеза заболевания следует, что пациентка жалоб на момент осмотра не имеет. По результатам маммографии выявлена фиброзно-узловая мастопатия справа (в задних отделах наружного квадранта 21 х 19 мм).

\section{Объективный статус}

Общее состояние Пациентки Х. удовлетворительное. Сознание ясное. Положение активное. Кожный покров и видимые слизистые бледно-розовые, чистые, увлажнены. Температура тела $36.7^{*}$ С. Дыхание в легких везикулярное, над всей поверхностью легких хрипы не выслушиваются. ЧДД - 17 в мин. Тоны сердца ритмичные, приглушены, ритм правильный. ЧСС - 76 в мин. АД - 125/70 мм.рт.ст. Живот не вздут, симметричный, при пальпации мягкий, безболезненный. Печень не уве- личена, край не пальпируется. Отеков нет. Со стороны мочеполовой системы патологий нет.

\section{Данные осмотра молочных желез}

Молочные железы симметричные, средних размеров.

Правая молочная железа пальпаторно - мягкая, без узловых образований, выделений нет, сосок не втянут, кожа не изменена. Регионарные лимфатические узлы не изменены.

\section{Результаты}

УзИ молочных желез при первичном обращении к онкологу: дифференциация тканей: структура молочных желез представлена жировой и фиброзной тканью; соотношение тканей, формирующую молочную железу: преобладает жировая ткань; визуализация протоков: протоки визуализируются, не расширены; визуализация позадисосковой области - свободная; нарушение УЗ-архитектоники - нет; диффузные изменения - нет; очаговые изменения - в структуре правой молочной железы на 21ч визуализируется гипоэхогенные образования с неровными лучистыми контурами, максимальным размером 15 × 23 мм. В правой подмышечный области измененные лимфоузлы максимальным размером 9 × 16 мм. На основании вышеперечисленного онкологом выставлен предварительный диагноз: Susp. бластома правой молочной железы. В связи с чем пациентке В тот же день проведена core-биопсия образования правой молочной железы и конгломерата лимфоузлов правой подмышечной области, полученные материалы направлены на патогистологическое и иммуногистохимические исследования в патологоанатомическое отделение Сургутской ОКБ. В течении 3 дней было получено патологоанатомическое заключение.

Также при осмотре на коже брюшной стенки справа ближе к подреберью выявлен рубец бледно-фиолетового цвета 1.5 x 1 см, слегка выступающий над поверхностью кожи. Со слов пациентки, ранее, 2 года назад, в этой области было пигментное образование бледно-коричневого цвета с эрозией. После курсов самолечения чистотелом эрозия эпителизировалась, цвет стал бледно-фиолетовым. Зуда в данном участке нет.

\section{Результаты}

По результатам патогистологического заключения из узлового образования правой молочной железы получена картина инвазивной карциномы молочной железы. Иммуногистохимическое исследование: в исследованном объеме материала морфологическая картина 
инвазивной карциномы молочной железы неспецифического типа (ICD-O code: 8500/3). Рецепторный статус: ЭР - 0 баллов, ПР - 0 баллов; позитивный HER2-статус (3+); индекс метки Кі-67 около 8-10\%.

Данные патогистологического заключения из лимфоузла правой подмышечной области - в исследованном материале морфологические показатели, крайне подозрительные в отношении метастатического поражения ткани лимфатического узла; для более достоверной верификации материал был направлен на ИГХ-исследование. С учетом ИГХ-исследования в исследованном объеме материала морфологические показатели, укладывающиеся в картину метастатического поражения ткани лимфатического узла; полученный иммунопрофиль наиболее соответствует метастазу меланомы в лимфатический узел.

Согласно рекомендациям АОР пациентка была дообследована и решением консилиума онкологов Сургутской ОКБ направлена на оперативное лечение в маммологическое-онкологическое отделение. Далее были приведены следующие оперативные вмешательства:

1. Радикальная резекция правой молочной железы с региональной лимфаденэктомией.

2. Иссечение поражения кожи передней брюшной стенки (область правого подреберья).

Окончательная гистология, полученная после операций, подтвердила онкологические диагнозы, которые выглядели следующим образом-

Первично-множественный синхронный рак:1) Рак верхненаружного квадранта правой молочной железы T1N0M IA стадия, радикальная резекция правой молоч- ной железы (01.2019 г.) 2) Метастаз меланомы в подмышечный лимфоузел справа из невыявленного первичного очага TxNxM1 IV стадия, иссечение поражения кожи передней брюшной стенки (правое подреберье).

Консилиумом онкологов Сургутской ОКБ в составе онколога-хирурга, врача-химиотерапевта, врача-радиолога, рентгенолога рекомендовано проведение 12 курсов АМХТ: еженедельный паклитаксел + еженедельный ТТ (транстузумаб). Курс лучевой терапии длТ СОД 44 Гр (по поводу рака молочной железы).

А лечение по поводу метастатической меланомы после определения статуса braf в виде 18 курсов ТT (транстузумаб) 486 мг каждые 21 день. План лечения составлен с учетом диагноза, клинических проявлений заболевания, тяжести заболевания, лабораторных, инструментальных методов исследования, согласно Клинических рекомендаций АОР.

Полное лечение завершено в мае 2020 г. В ходе лечения и после его завершения не отмечалось ни рецидивов, ни прогрессирования заболеваний. В настоящее время пациентка находится на диспансерном учете у онкологов Сургутской ОКБ и проходит обследования каждые 3 месяца согласно Клиническим рекомендациям AOP.

\section{Зак^ючение}

Своевременная диагностика, верно поставленный диагноз, а также правильное лечение приводит к длительной ремиссии онкологического заболевания и улучшению качества жизни.

\section{ЛИТЕРАТУРА}

1. Наумова Н.В. Первично-множественные злокачественные опухоли: трудности диагностики в практике врача-терапевта / Н.В. Наумова, Л.Н. Романчук // Журнал Гродненского государственного медицинского университета.— 2015.— № 3 (51). — C. 94-96.

2. Фролов И.М. Клинические и молекулярно-генетические особенности первично-множественного рака (литературный обзор) / И.М. Фролов, Е.А. Кудинова, Н.И. Рожкова // Вестник РНЦРР.— 2012. - № 12.- С. 1-17.

3. Проблемы первично-множественных процессов у больных раком молочной железы / Ю.С. Сидоренко, Т.В. Шелякина, Е.В. Титова и др. // Сибирский онкологический журнал. - 2010.— № 1.- С. 18-22.

4. Справочник по онкологии / Под ред. Д. Кэссиди, Д. Биссета, Р.А. Дж. Спенса, М. Пэйн. - М., 2010. - 440 с.

5. Multiple primary synchronous malignant tumors / A. Testori, U. Cioffi, M. De Simone et al. // BMC Research Notes. — 2015. — № 8. — P. 730.

6. Billroth T. Die allgemeine chirurgische / T. Billroth // Pathologie und Therapie. — Berlin, 1889.

7. Hanlon F.R. Multiple primary carcinoma / F.R. Hanlon // Am J Cancer.— 1931.—Vol.15. — P. 2001-2012. 